\title{
Metrics to assess how longitudinal channel network connectivity and in-stream Atlantic salmon habitats are impacted by hydropower regulation
}

\section{Authors and affiliations}

Willem Bastiaan Buddendorf ${ }^{\mathrm{a}}$, Iain A Malcolm ${ }^{\mathrm{b}}$, Josie Geris ${ }^{\mathrm{a}}$, Mark Wilkinson ${ }^{\mathrm{c}}$, Chris Soulsby ${ }^{\mathrm{a}}$

a: Northern Rivers Institute, School of Geosciences, University of Aberdeen, St. Mary's, Elphinstone Road, Aberdeen, UK, AB24 3UF

${ }^{\mathrm{b}}$ : Marine Scotland Science, Freshwater Fisheries Laboratory, Faskally, Pitlochry, UK, PH16 5LB

c: James Hutton Institute, Environmental and Biochemical Sciences, Aberdeen, UK, AB15 8QH

\section{Corresponding author address:}

Bas Buddendorf

Northern Rivers Institute

School of Geosciences

University of Aberdeen

St. Mary's

Elphinstone Road

Aberdeen

UK

AB24 3UF

+4471224273696

bas.buddendorf@abdn.ac.uk

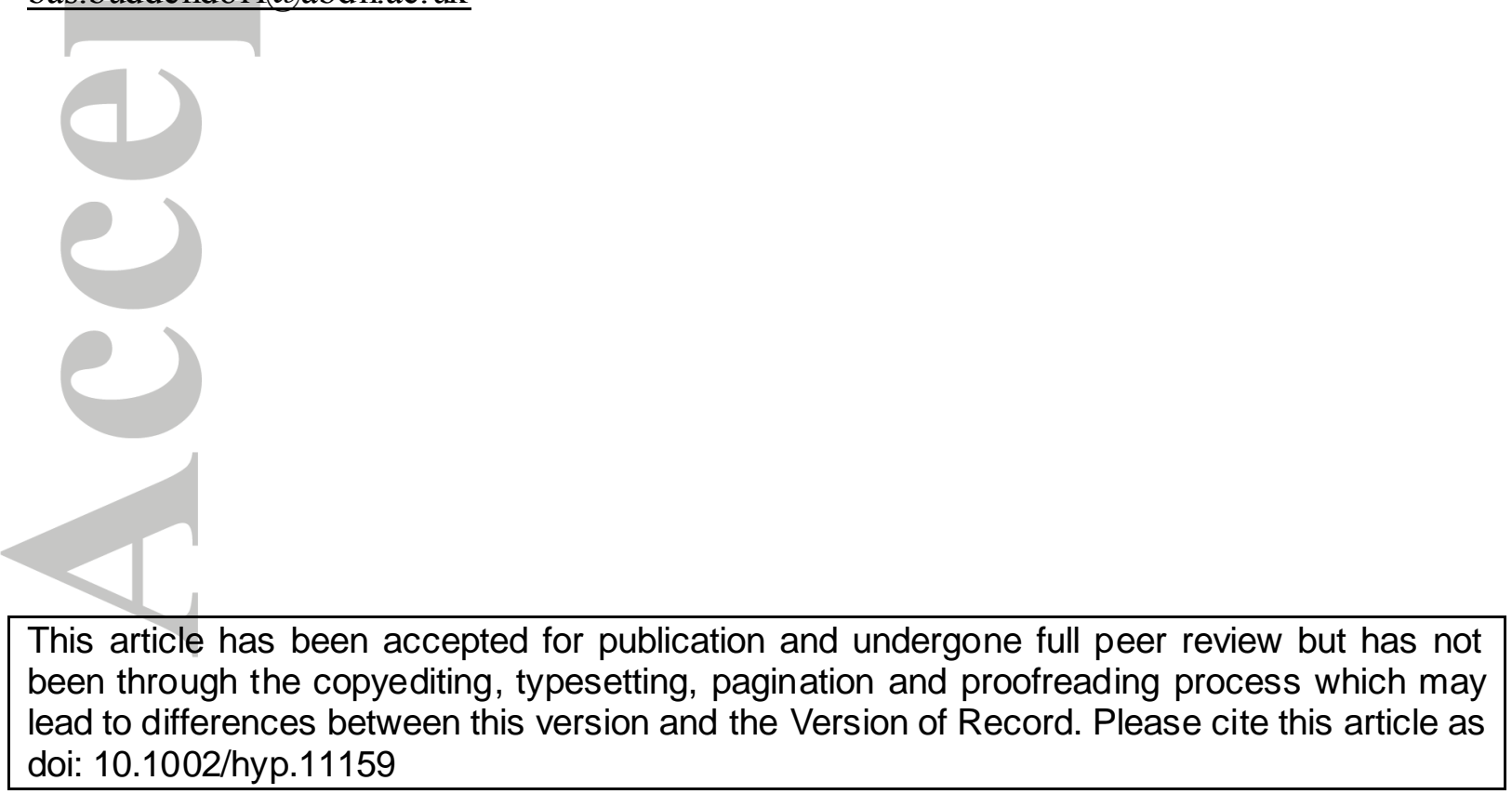




\title{
Metrics to assess how longitudinal channel network connectivity and in-stream Atlantic salmon habitats are impacted by hydropower regulation
}

\author{
Running head \\ Regulation impacts on channel connectivity and Atlantic salmon habitat
}

\begin{abstract}
Habitat fragmentation in channel networks and riverine ecosystems is increasing globally due to the construction of barriers and river regulation. The resulting divergence from the natural state poses a threat to ecosystem integrity. Consequently, a trade-off is required between the conservation of biodiversity in channel networks and socio-economic factors including power generation, potable water supplies, fisheries and tourism. Many of Scotland's rivers are regulated for hydropower generation but also support populations of Atlantic salmon (Salmo salar L.) that have high economic and conservation value. This paper investigates the use of connectivity metrics and weightings to assess the impact of river barriers (impoundments) associated with hydropower regulation on natural longitudinal channel connectivity for Atlantic salmon. We applied two different weighting approaches in the connectivity models that accounted for spatial variability in habitat quality for spawning and fry production and contrasted these models with a more traditional approach using wetted area. Assessments of habitat loss using the habitat quality weighted models contrasted with those using the less biologically relevant wetted area. This highlights the importance of including relevant ecological and hydrogeomorphic information in assessing regulation impacts on natural channel connectivity. Specifically, we highlight scenarios where losing a smaller area of productive habitat can have a larger impact on Atlantic salmon than losing a greater area of less suitable habitat. It is recommended that future channel connectivity assessments should attempt to include biologically relevant weightings, rather than relying on simpler metrics like wetted area which can produce misleading assessments of barrier impacts.
\end{abstract}

KEY WORDS: hydropower; river regulation; Atlantic salmon; longitudinal channel connectivity; river network; weighting

\section{Introduction}

Habitat fragmentation is a major cause of biodiversity loss (e.g., Bascompte and Sole, 1996; Dudgeon et al., 2006; Grill et al., 2015). In riverine ecosystems anthropogenic river fragmentation is caused primarily by the construction of barriers such as dams, weirs and culverts (Pringle, 2001). Although the size and scale of barriers is highly variable, ranging from small culverts to large dams, they all have the potential to fully or partially block access to and from parts of the channel network, thus moving the system away from the natural connected state that maintains ecological function (Tetzlaff et al., 2007). With increasing human population size, there is an increasing demand on water resources for power generation, potable supply and irrigation. These demands are expected to significantly and rapidly increase the number of dams and the degree of river regulation globally (Zarfl et al., 2014; Grill et al., 2015). Concerns have been raised that an increasing degree of river regulation is likely to alter the heterogeneity and connectedness of river systems (Poff et al., 2007; Tockner et al., 2011), further threatening the integrity of their dependent ecosystems. 
The application of graph theory and connectivity indices is a powerful approach for quantifying the impacts of regulation on the hydrological connectivity of channel networks. Such indices have been widely used in terrestrial landscape ecology to investigate the role of connectivity in determining the ability of species to persist in fragmented landscapes (e.g., Urban et al., 2009; Dale and Fortin, 2010; Gilarranz and Bascompte, 2012; Rubio and Saura, 2012). More recently these approaches have been extended to explicitly consider the specific structure of river ecosystems. Rivers occur as dendritic hydrological and ecological networks (Campbell Grant et al., 2007), and connectivity can be assessed using a variety of approaches and metrics, depending on the aims of the research, the target species and the ir life history characteristics (Peterson et al., 2013). For example, a group of commonly used connectivity indices are based on centrality (Jordan et al., 2007), a structural characteristic of network elements (e.g., habitat patches or reaches) that puts specific emphasis on positional importance and network structure in determining the system's connectivity (Urban et al., 2009; Erös et al., 2011). However, these indices often fail to give emphas is to the role of habitat characteristics and the life history needs of migratory species. Therefore, not all indices of connectivity are equally suitable for application to migratory fish species such as anadromous salmonids. Indeed, connectivity indices have been developed to address this issue by including additional information on, for example, passability of barriers, (upstream) migration ability, patch size, habitat quality, population structure, and life history traits (Schick and Lindley, 2007; Cote et al., 2009; Branco et al., 2012; McKay et al., 2013). This has led to successful application of graph theory and connectivity indices in understanding channel networks and guiding the restoration and management of riverine systems (e.g., Segurado et al., 2013; Branco et al., 2014; Mahlum et al., 2014).

In the absence of detailed biological information or appropriate models of habitat quality, a common approach is to assume that all habitat is of equal quality and assess habitat loss or impacts to connectivity using simple metrics such as wetted area, river length, or volume of river reaches (e.g., Cote et al., 2009; Grill et al., 2014). A major drawback with such measures is a lack of ecological and hydrogeomorphic detail, potentially leading to over- or under-estimation of the impacts of barriers on connectivity depending on the relative quality of available habitat. In practice this means that there is an implicit risk that assessments of impacts on natural channel connectivity focus on areas that may only play a minor role in supporting local communities, and thus limit the quality and relevance of such assessments.

In Scotland, many rivers are regulated for hydropower. River barriers have been created (i.e., dams and diversions) that can change the spatial and temporal connectivity within river networks. Yet, at the same time they sustain substantial populations of Atlantic salmon (Salmo salar L.), a species of high economic and conservation value, and other sensitive species like the freshwater pearl mussel (Margaritifera margaritifera L.) (Jackson et al., 2007; Birkel et al., 2014; Quinlan et al., 2015). The impacts of river regulation for hydropower on the availability and quality of salmon habitat are complex and not fully understood. Atlantic salmon have a range of habitat requirements, depending on life-stage and the unique characteristics of specific river systems (e.g., Tetzlaff et al., 2008; Malcolm et al., 2012; Milner et al., 2012; Nislow and Armstrong, 2012). Therefore, the use of very simple rules or metrics to assess the impacts of anthropogenic activity is unlikely to be adequate for the management of salmon populations (Malcolm et al., 2012; Milner et al., 2012). Improved understanding of the impacts of barriers on Atlantic salmon habitat, set within an interdisciplinary framework that addresses hydrogeomorphic and ecological 
factors, is vital to advance our knowledge on processes that influence the hydrological cycle and ultimately determine the functioning of lotic environments.

Our work aims to integrate hydrogeomorphic and ecological aspects into a spatially explicit connectivity framework that can be applied at multiple spatial scales in river networks. Such an approach can more reliably highlight areas that are important to maintain in-stream processes that provide good quality habitat supporting the conservation of salmon, and contribute to their sustainable management of in an era of marked environmental change (Goode et al., 2013). The value of such an approach is illustrated using the case study of the

River Lyon, an intensively studied tributary of the River Tay in Scotland with a substantial hydropower influence where previous studies provide valuable background data (Mulet, 2004; Jackson et al., 2007; Geris et al., 2015). The objectives of this study are: 1) To assess the impacts of river regulation on longitudinal connectivity, i.e., the likely ability of Atlantic salmon individuals to pass barriers located along the longitudinal profile of a river network (Cote et al., 2009; Mahlum et al., 2014), where we apply a weighting for habitat quality using two approaches based on (a) information on reach type morphology (sensu Montgomery and Buffington, 1997), and (b) predicted salmon fry density from the Scottish national fry density model (Millar et al., 2015); 2) To determine the importance of such weighting approaches, we compare results with the more commonly used wetted area weighting to assess how the different approaches can (mis)-inform assessments of regulation impacts; and 3 ) Estimate the likely loss of production brought about by different impoundments.

\section{Methods}

\section{Study site}

The River Lyon is a major tributary of the River Tay, located in the Central Highlands of Scotland (Figure 1). The Tay is Scotland's largest river catchment and an important river system for salmon fishing. The $49 \mathrm{~km}$ long River Lyon drains an area of $391 \mathrm{~km}^{2}$, with elevations ranging between 97 and $1211 \mathrm{~m}$ AMSL. Owing to its glacial history, the catchment has steep hillslopes and tributary streams, with a wide gently sloping valley bottom. Hydropower infrastructure was developed in the 1950s, since then the river has been heavily regulated for hydropower (Geris et al., 2015; Soulsby et al., 2015), and so, in addition to natural semi-passable barriers (i.e., waterfalls that are passable under certain conditions), there are a number of manmade barriers to fish migration (i.e., dams; Figure 1A). Passability of barriers is based on the Scottish Environmental Protection Agency (SEPA) dataset on barriers to fish migration (Table 1). The dams span the entire width of the river and their passability depends on the presence or absence of fish passes. There are two large dams on the main stem of the river. The upstream Lubreoch dam is a large buttress type dam without a fish pass that prevents any access to the upper catchment (Figure 1A). The second barrier (Stronuich reservoir dam) receives water released from Lubreoch and transfers it to a neighbouring catchment. A fish pass is present and it is assumed that this barrier is fully passable. It is likely that passability for salmonids will be less than $100 \%$ in either an up- or downstream migration direction (e.g., Bunt et al., 2012; Noonan et al., 2012). Thus, our assumption of $100 \%$ passability may lead to an overestimation of connectivity. However, given the large uncertainty around the passability of barriers (Bunt et al., 2012), which has not been quantified for the Stronuich dam fish pass, the choice is considered reasonable. There are also two smaller dams without fish passes, located on tributary streams that enter the Lyon downstream of Lubreoch and Stronuich dams, and are assumed to be impassable barriers (Figure 1A). Finally, there are two waterfalls on the main stem of the river downstream of Stronuich dam. Based on flow regime, characteristics of the feature, and the ability of salmon to pass objects, we assume that these are passable $80 \%$ of the time (i.e. in 
all but the lowest flows). It is assumed that all barriers are fully passable in the downstream direction. Further details of the Tay and Lyon catchment areas and regulation schemes are reported by Birkel et al. (2014); Geris et al. (2015); and Soulsby et al. (2015).

\section{Connectivity index}

To assess the impact of regulation on connectivity in the Lyon channel network, we used the Dendritic Connectivity Index for anadromous fish species $\left(\mathrm{DCI}_{\mathrm{d}}\right)$ (Cote et al., 2009; Mahlum et al., 2014). The index gives a global measure of a systems connectivity and it can inform habitat management by indicating which sections of the river network are important to maintain high levels of connectivity. It allows a weighting for habitat quality and assignment of different passability values to barriers, the impact of which is then accounted for cumulatively. The $\mathrm{DCl}_{d}$ and $\mathrm{DCl}_{\text {sectional }}$ indices include both upstream and downstream migration. For downstream passability we have assumed a value of 1, i.e., in the downstream direction barriers are always passable, making it effectively identical to the habitat connectivity index for upstream passage developed by McKay et al. (2013). Connectivity is addressed for the anadromous life cycle as a whole by including upstream and downstream migration and thus allows us to also look at impacts of regulation on out migrating parr and smolts, and the importance of individual sections in determining the system's connectivity ( $\mathrm{DCI}_{\text {sectional }}$ ) (Mahlum et al., 2014). To determine the $\mathrm{DCI}_{\text {sectional, }}$ each section in the network is considered to be the start of the network and subsequently the connectivity with the rest of the network is calculated. See Supplementary material for a detailed description of these ind ices.

\section{GIS analysis for connectivity}

Readily available GIS datasets were collated for the analysis (Table 1). After performing basic pre-processing of the raw $5 \mathrm{~m}$ digital terrain model (DTM) with the Hydrology toolbox from ESRI ArcGIS version 10.2.1, the DTM was used to derive the river network. Reaches that were located above natural impassable barriers were excluded from the river network, where the impassability classification is based on the SEPA barriers dataset. Attributes were assigned to each river reach in the river network; the latter consists of $50 \mathrm{~m}$ reaches with additional nodes at confluences. First, we used GIS data to determine Wetted Area (WA) from width data, available in the Ordnance Survey Master Map River Polygons dataset for South Lanarkshire and Perth-Kinross, at $5 \mathrm{~m}$ intervals averaged for $50 \mathrm{~m}$ reaches. Subsequently, average widths were multiplied with reach lengths to determine the reach area. Lochs were added to reaches separately, based on the OS Mastermap dataset (Figure 2A). Second, empirical reach classification data (Montgomery and Buffington, 1997) was assigned to reaches downstream of the Lubreoch dam by Mulet (2004). It is recognised that there are limitations to the use of the classification based on surface flow types, developed by Montgomery and Buffington (1997). Primarily, the classification potentially suffers from user bias and the spatial extent of reach types can be difficult to delineate (Woodget et al., 2016), thus introducing a potential source of uncertainty. Quality multipliers were then applied to the reach types (see Table 2) to reflect their value as Spawning Habitat (SH) following hydraulically-based habitat utilisation data for adult salmon spawning in similar Scottish rivers (Moir et al., 2004). The available data on spawning habitat preference of salmon in Scottish rivers is limited. Moir et al. (2004) have mapped reach types in two Scottish salmon rivers and the percentage usage of reach types for spawning within the two rivers, the classification results show that not all the same reach types are shared between the two rivers in Moir et al. (2004) and the river Lyon. Therefore, we have attributed relative scores for quality of reach types as spawning habitat using the data in Moir et al. (2004) in combination with available knowledge on spawning habitat for Atlantic salmon (e.g., Gibson, 1993; Armstrong et al., 2003) as a guideline to get reasonable estimates of spawning habitat quality. 
It should be noted that Atlantic salmon in Scotland do not spawn in lochs (Gibson, 1993) and therefore the quality multiplier has a value of 0.01 , i.e., only $1 \%$ of loch area was included to represent the low importance of lochs in terms of providing habitat (Figure 2B and Figure 3). Third, the Scottish national salmon fry density model developed by Millar et al. (2015) was used to predict salmon fry densities for points spaced at $100 \mathrm{~m}$ intervals along the river network. Density predictions were assigned to the $50 \mathrm{~m}$ reaches based on the nearest prediction point. Full details of the model are provided by Millar et al. (2015). However, in brief, the model predicts salmon fry densities from a large (1800 sites) electrofishing dataset covering the whole of Scotland using a suite of spatial, temporal and GIS derived habitat covariates. Model output was successfully fitted to available electrofishing data and GIS covariates used in the model are robust between sites increasing the utility of the model over locally derived production models (Millar et al., 2015). For the purposes of this study, the model was used to predict fry densities for a particular day of the year (Day 250), and for the year with the highest observed national fry production (2003). As such the output can be interpreted as an estimate of fry production (FP) in a good year having accounted for habitat. By summing density estimates over the river network it was possible to obtain estimates of fry production in the presence or absence of barriers with associated uncertainty (Figure 1C and $2 \mathrm{C}$ ).

To simplify the river network and expedite the analysis of the connectivity indices, reaches were summarised based on the location of barriers, resulting in a total of 9 river sections (Figure 1B).

\section{Weighting}

To determine the relative ecological importance of reaches, we applied weights based on the stream attributes described above. The different weightings inherently induce different assumptions about the value of the reaches. Weighting for simple WA puts emphasis on larger wetted areas and assumes that all wetted habitat is of equal ecological value, i.e., losing them will have a large impact on connectivity; weighting for $\mathrm{SH}$ puts emphasis on response reach types, i.e., reaches where the sediment transport capacity is smaller than sediment supply leading to pool-riffle and wandering reach types, as opposed to transport reach types where sediment transport capacity exceeds sediment supply forming step-pool and cascade reach types (Montgomery and Buffington, 1997). Thus, losing them will have a larger impact on connectivity; weighting for FP puts emphasis on areas that are predicted to have higher juvenile densities, thus reflecting both wetted area and habitat quality, and has the strongest direct link to guiding management, where losing areas with higher predicted densities has a higher impact on connectivity.

\section{Connectivity simulations}

We used the Fish Passage Extension (FIPEX version 2.2.1) for ArcGIS (version 10.2.1) to compute the $\mathrm{DCI}_{\mathrm{d}}$ and $\mathrm{DCI}_{\text {sectional }}$. Barriers to fish migration were added in a downstream sequence from the top of the catchment to the mouth. This approach enabled us to investigate the cumulative impact of each of the individual barriers on the overall connectivity, regard less of their origin (i.e., manmade or natural). Because any assessment of connectivity losses should be compared with the natural state that includes natural barriers, the impact of artificial barriers was assessed as a proportion of the natural connectivity state. DCI sectional, $_{\text {, }}$ was only calculated where all barriers were present in the system. 
Assessing losses in fry production associated with barriers

The construction of the Lubreoch and Stronuich dams led to changes in the topography of the river network by increasing the size of Loch Lubreoch and the creation of the Stronuich reservoir (Figure 1A vs 1D). Therefore, to determine the potential loss of fry production between historic and contemporary river states, it was first necessary to construct preimpoundment topographic maps for the river system. This was achieved using an Ordnance Survey map that pre-dated construction of the dams in Glen Lyon (Figure 1D; Table 1). Additional GIS covariates for the density model were collected for those sections that were riverine (rather than lacustrine) in the historic state. Next, the same approach to predict densities for the historic river network was used as described for the contemporary river network (see section: GIS analysis for connectivity). For the purposes of this paper it was assumed that production and wetted areas below the dams have not been affected by impoundment. It is recognised that this is an over-simplification and that post-construction production has probably been reduced even in remaining river reaches, but this provides a reasonable estimate of the minimum impact of dam construction.

To assess uncertainty in the difference between the pre- and post- impoundment production estimates a parametric bootstrap was performed. In short, for both scenarios, 1000 realisations of the model coefficients were created for each scenario assuming multivariate normality and these were used to predict production. Confidence intervals were calculated using the $5^{\text {th }}$ and $95^{\text {th }}$ percentile of model realisations. The change in production was calculated as a simple ratio of the production estimates.

\section{Results}

Impacts of different barriers and weighting on connectivity indices

When both natural and anthropogenic barriers were considered purely as constraints on fish migration, the $\mathrm{DCI}_{\mathrm{d}}$ index for the Lyon system was $18.2 \%, 73.9 \%$, and $74.7 \%$ for $\mathrm{WA}, \mathrm{SH}$, and FP weighting, respectively (Table 3 ).

Between the weighting approaches there are major differences in cumulative impact of the individual barriers on longitudinal connectivity. The WA weighted connectivity index indicated a severe effect of Lubreoch dam (i.e., 76.5\% drop) and had minimal effects potentially associated with natural barriers on connectivity, i.e., a maximum drop of $3.4 \%$, for the waterfall furthest downstream (Table 3). In contrast, the weighting for SH and FP suggested that the impact of the Lubreoch dam is almost an order of magnitude smaller and the drops in cumulative connectivity are 10.3 and 5\%, respectively. Additionally, larger impacts were potentially associated with natural barriers on the main stem, i.e., drops of 12$14.2 \%$, for SH and FP weighting, respectively (Table 3). Compared to WA weighting, these drops are at least 3.5 times greater. In all weighting scenarios, the drops in cumulative connectivity caused by the small dams on tributary streams are small. The reason for this is, that they constitute small wetted areas but at the same time contain little suitable spawning habitat and not predicted to be very productive. This shows that depending on the type of weighting, the impact of barriers depends strongly on its characteristics and location. Additionally, the SH and FP weightings suggest that losing less but more suitable/productive areas can have a larger impact than losing larger areas of unsuitable/unproductive habitat (Table 3).

Put into perspective of natural connectivity, where only artificial barriers to fish migration are considered, the overall connectivity as a percentage of natural connectivity was $27 \%, 91.6 \%$, and $95.2 \%$ for WA, SH, and FP weighting, respectively (Table 4). It is clear that for all 
weightings Lubreoch dam causes the main decrease, although the scale of impact differs greatly between WA weighting and weighting for $\mathrm{SH}$ and FP (i.e., 73\% drop for WA, compared to $8.4 \%$ and $4.8 \%$ for $\mathrm{SH}$ and $\mathrm{FP}$, respectively).

When the role of different river sections in 'providing connectivity' is considered, the WA weighting suggests that the area upstream of Lubreoch dam is very important for connectivity (Figure 4). Again, in stark contrast, the connectivity indices weighted for SH and FP suggested that the downstream parts of the network were more important for sustaining high levels of connectivity (Figure 4). The two barriers that were placed on steep and small tributary streams played a minor role in determining within-network connectivity. They constituted small wetted areas, little of which was suitable for spawning or fry production.

\section{Loss of production due to construction of barriers}

It is estimated that the introduction of anthropogenic barriers to the Glen Lyon system would have resulted in a $21 \%(95 \%$ CI $16-26.5 \%)$ reduction in fry production relative to the natural state. Based on the output from the parametric bootstrapping, none of the simulations predicted a higher production in the current system.

\section{Discussion}

Impacts of barriers on longitudinal connectivity

The impacts of anthropogenic barriers on the $\mathrm{DCI}_{\mathrm{d}}$ index in the river Lyon was relatively small for the SH and FP weighted scenarios. The results are, naturally, strongly influenced by our assumptions on the passability values, which have not been quantified for the Lyon. Consequently, in the absence of a thorough empirical assessment of passabilities, a difficult and onerous undertaking, we have to rely on knowledge of the local system in terms of flow regime and general investigations into efficiency of similar fish bypass systems.

The validity of the assumption that barriers are always passable in a downstream direction is hard to ascertain, but may to some extent be realistic in the Lyon system where the lochs are relatively small, and juvenile fish can pass via surface spillways and through regulating outlets. However, there are some factors that can effectively reduce passability of barriers and potentially lead to a substantial increase in fish mortality. Firstly, turbine passage itself can result in significant mortality. A number of studies have assessed the mortality rates of salmonids passing through turbines and culverts (Mathur et al., 1996; Čada, 2001; Budy et al., 2002; Ferguson et al., 2006; Scruton et al., 2008; Calles and Greenberg, 2009; Stephenson et al., 2010; Deng et al., 2011; Keefer et al., 2013). Depending on the particular dam type, fish species, and unique characteristics of the river, the mortality rates vary between 6-69\% (Mathur et al., 1996; Keefer et al., 2013). Even where fish are able to pass a barrier, survival can be affected subsequently through sub-lethal effects (Budy et al., 2002; Ferguson et al., 2006; Stich et al., 2015). Secondly, in recent years, there have been increasing concerns about the potentially low attraction rate of some fish bypasses for both up- and downstream migration and the delay to migration this can cause. Although, small weirs and barriers are not present in the river Lyon, they have been shown to also have a marked influence on the speed of downstream migration, especially under low-flow conditions and even un relatively natural river systems (Gauld et al., 2013). Such delays have indirect effects on mortality through increased predation risk by e.g., piscivorous birds like sawbill ducks (Merganser spp.), resident Brown trout (Salmo trutta L.), and Northern pike (Esox lucius L.) (not present in river Lyon) for smolts, predation by e.g., otters (Lutra lutra L.) for adults, and exhaustion (Calles and Greenberg, 2009; Gustafsson, 2010). Furthermore, delays in migration can have serious consequences for smolts migrating out to sea. Smolts 
have a window of opportunity to migrate to sea when they are physiologically ready to enter the saline environments of the estuary and the sea (McCormick et al., 1998). Delays can lead to desmoltification (Thorstad et al., 2012), which increases the risk of mortality, but may also lead to a mismatch in their timing of sea entry which potentially reduces their chances of survival and returning as adults for spawning (Scheuerell et al., 2009). These are important issues, as the effects of direct and indirect mortality, and delays are not currently included in our approach, or in connectivity metrics in general, whereas the implications could be severe. Taken to gether this suggests that in reality our $\mathrm{DCI}_{\mathrm{d}}$ and $\mathrm{DCI}_{\text {sectional }}$ values are likely to be overestimated.

When considering upstream migration, the assumptions made for impassable barriers are more reasonable, as without some form of bypass system migration is not possible. In the case of the two natural barriers and the fish bypass at Stronuich dam, our assumptions can substantially affect the results as assuming lower passability values would decrease the connectivity values and vice versa. With the available knowledge on the effect of flow regime on temporal changes in passability (Shaw et al., 2016), and a general lack of reliable information on fish bypass efficiency (Bunt et al., 2012; Noonan et al., 2012), the values we used are thought to be reasonable but might be overestimating the true passability values of anthropogenic barriers and under estimating passability of natural barriers.

Despite the increasing use of connectivity metrics for assessing the potential impacts of barriers, the approach has limitations in its application to large-scale systems. For example, there are concerns about the diversion from the natural state because regulation for hydropower can have additional effects on temperature regime (Imholt et al., 2013), instream hydraulic conditions, food availability and hydrochemistry (Jackson et al., 2007). Yet, the impacts of regulation do not propagate well across scales, effects seen at local scales can be balanced out at larger scales (Birkel et al., 2014; Geris et al., 2015; Soulsby et al., 2015). This has further implications for the use of generic measures to infer habitat quality over large scales, as they may not capture the potentially large impacts at local scales.

It remains to be seen whether the strongly contrasting assessment of barrier effects using connectivity metrics with different weightings would also occur in other river catchments. The impact of barriers in the river Lyon should be considered in the context of the highly linear morphology of the river network. The absence of suitable habitat in the steep tributary streams means that any barriers on tributaries have almost no effect and barriers on the main stem affect a relatively small proportion of the total river network (i.e., only the main stem sections). In a river system that has a more branched network structure where tributary streams make up a relatively larger proportion of the total river network, are less steep and easily accessible to migrating salmon, the impact of barriers could be substantially bigger.

\section{Comparison of weighted connectivity indices and wetted area approach}

Our work has shown that using wetted area as an indicator for ecological suitability of habitat, without the inclusion of hydrogeomorphically and ecologically relevant information, has the risk to mis-inform assessments of regulation impacts on hydrological processes governing habitat availability and suitability. For example, had a wetted area weighting been considered, the results suggest the biggest gain per unit area would be to improve fish passage beyond Lubreoch dam, due the large wetted area of Loch Lyon compared to the rest of river's wetted area. In contrast, our modelling work suggests that the impacts on hydrologic connectivity for the Lubreoch hydropower dam is relatively minor, because it is not productive and contains very little suitable area for spawning habitat, rather most 
productive habitat in the catchment has been maintained under current conditions. The question then becomes, what is the appropriate scale to try and characterise habitat quality? For example, at relatively small scales, there are studies where high-resolution remotely sensed imagery has been used to map in-stream habitat elements over river lengths ranging between 1 and $5 \mathrm{~km}$ (e.g., Marcus et al., 2003; Tamminga et al., 2015), this could provide insights into which reaches in a river network are likely to provide the most suitable habitat per unit area assuming that there are strong links between hydromorphological classification and ecological value. However, when assessing connectivity with the aim of understanding changes in hydrologic processes that ultimately govern habitat availability in larger systems (entire river systems and areas larger than $1000 \mathrm{~km}^{2}$ ) with limited detailed local knowledge, a trade-off may have to be made between small-scale detailed knowled ge and large-scale trends where it is necessary to use proxies for habitat that can be used to model habitat quality.

Two alternative types of weighting were applied in this study. These suggest that even coarse scale information can provide insight into regulation impacts in a way that is more likely to be effective than using an approach like wetted area weighting or assessments using river length. Although the resolution at which we collected our geomorphic data $(50 \mathrm{~m}$ reaches) was relatively coarse and such that some small-scale details may be missed, it is unfeasible in terms of time and costs (a common limitation) to obtain in-stream habitat assessments for the entire river, unless significant advances are made in the use and costs of remote sensing techniques that can characterise depth and substrate sizes at large scales using e.g., green LiDAR or structure-from-motion photogrammetry based techniques (Woodget et al., 2016). The fry density model provides us with a useful tool to make predictions at an intermediate resolution across large spatial scales, i.e., for the whole of Scotland (Millar et al., 2015). In the absence of large datasets required to develop models like the fry density model, similar, albeit less detailed, models may be developed that can give insight into the importance of river sections in providing suitable habitat. For example, using presence/absence data available for part of a river network and GIS covariates, some studies have shown the power of statistical modelling techniques to model the likelihood of species to be present/absent over large spatial scales (De'ath and Fabricius, 2000; Leathwick et al., 2008; Branco et al., 2014).

\section{Loss of production due to construction of barriers}

We recognise that, although relative production values between the two scenarios are robust, the uncertainties in the absolute predictions from the fry density model are large. These result from the patchy nature of fry abundance (depending on whether fish spawned nearby in the previous years), error propagation related to uncertainties around the fry density model, and the GIS covariates, see Millar et al. (2015). Therefore, the predictions need to be interpreted as being indicative rather than absolute. Another assumption is that production and wetted area below dams have not been affected by impoundment. In reality, the areas below dams could be producing lower or higher numbers of fish due to changes in discharge regime or that changes in discharge have reduced or increased the channel area compared with the historical situation. The consequence of the latter is that the multiplier for channel width is under- or overestimated and would thus lead to an under- or overestimation of the actual reach area and therefore of production. In the case of the river Lyon, a reduction in production of approximately $20 \%$ could be considered a modest, though still significant loss. Although this is due to a loss of habitat for a protected and economically important species, habitat losses need to be contextualised in the light of other societal goals such as clean energy and reduced C emissions (Lazzaro and Botter, 2015). In other river networks, with 
different characteristics or where impassable barriers are placed lower in the system, the potential losses could be much greater.

The results in our study depended strongly on our focal species; the impact of barriers is not negative by default. On the one hand some native species, like Brown trout (Salmo trutta L.), may benefit from the construction of barriers and the consequent increase in reservoir sizes. On the other hand, Northern pike, which is non-native to much of Scotland, also benefits from increased reservoir sizes, but could lead to issues with higher mortality rates of migrating salmon smolts due to predation. Moreover, in some areas barriers are being constructed on purpose to prevent invasive species from entering a sensitive system, thus barriers might also serve to protect species from being outcompeted (Buktenica et al., 2013).

The effects of river regulation through the construction of barriers should be viewed in the context of the effects of natural barriers that are already present. Manmade barriers can reduce or increase the effect of natural barriers (e.g., by increasing, decreasing flow). Thus, different types of regulation may have a different impact on connectivity. For example interbasin transfers of water have effectively increased exchange between otherwise disconnected systems in continental Europe (Tockner et al., 2011). This has lead to an increase in connectivity, although the effects can be adverse as the risk of disease spread and invasive species increases dramatically (Poff et al., 2007).

\section{Conclusion}

We have assessed the impacts of river regulation on longitudinal connectivity using connectivity indices. Often, wetted area is used to infer the amount of lost habitat and the consequences this might have for in-stream processes. We used two different types of weighting and compared these to the wetted area approach. Our results indicate that using wetted area could greatly misinform assessments of such impacts. Instead, we suggest that the inclusion of more relevant hydrogeomorphic and ecological details can improve our ability to identify those areas in the river network that are able to maintain high levels of connectivity. Focussing on those areas could increase the ability regulated system to provide suitable in-stream conditions important for ecosystem functioning. Moreover, our results showed that losing less but more suitable and productive areas can have a larger impact on connectivity than losing more but less suitable and productive areas. This is important in terms of setting flow and process related targets for the regulation of rivers and floodplains globally. Changes to current guidelines for specific systems should be made with appropriate caution as it is necessary to first investigate the effect of scale and, in the case of nested catchments, the inclusion of other regulated rivers within the catchment to ascertain the robustness of the approach. Moreover, any management and conservation decision needs to be based on a solid understanding of what the ecological targets are. This study has looked at a fundamental element (i.e., longitudinal habitat connectivity) that makes up the habitat template, but needs to be part of a holistic approach in which the spatial and temporal aspects of, for example, hydraulic conditions, temperature, community dynamics, and sediment budgets are considered.

\section{Acknowledgements}

Thanks to the Scottish Government's Hydro Nation Scholars Program for funding WBB to do this research. Also, many thanks to colleagues at Marine Science Scotland and the James Hutton Institute for providing some of the datasets used in this work. The authors thank the anonymous referees for constructive feedback on the manuscript. 


\section{References}

Armstrong JD, Kemp PS, Kennedy GJA, Ladle M, Milner NJ. 2003. Habitat requirements of Atlantic salmon and brown trout in rivers and streams. Fisheries Research, 62: 143170. DOI: http://dx.doi.org/10.1016/S0165-7836(02)00160-1.

Bascompte J, Sole RV. 1996. Habitat Fragmentation and Extinction Thresholds in Spatially Exp licit Models. Journal of Animal Ecology, 65: 465-473. DOI: 10.2307/5781.

Birkel C, Soulsby C, Ali G, Tetzlaff D. 2014. Assessing the cumulative impacts of hydropower regulation on the flow characteristics of a large Atlantic Salmon river system. River Research and Applications, 30: 456-475. DOI: 10.1002/rra.2656.

Branco P, Segurado P, Santos JM, Ferreira MT. 2014. Prioritizing barrier removal to improve functional connectivity of rivers. Journal of Applied Ecology, 51: 1197-1206. DOI: 10.1111/1365-2664.12317.

Branco P, Segurado P, Santos JM, Pinheiro P, Ferreira MT. 2012. Does longitudinal connectivity loss affect the distribution of freshwater fish? Ecological Engineering, 48: 70-78. DOI: 10.1016/j.ecoleng.2011.05.008.

Budy P, Thiede GP, Bouwes N, Petrosky CE, Schaller H. 2002. Evidence linking delayed mortality of snake river salmon to their earlier hydrosystem experience. North American Journal of F isheries Management, 22:35-51. DOI: 10.1577/15488675(2002)022<0035:ELDMOS>2.0.CO;2.

Buktenica MW, Hering DK, Girdner SF, Mahoney BD, Rosenlund BD. 2013. Eradication of nonnative Brook trout with electro fishing and Antimycin-A and the response of a remnant Bull trout population. North American Journal of F isheries Management, 33: 117-129. DOI: 10.1080/02755947.2012.747452.

Bunt CM, Castro-Santos T, Haro A. 2012. PERFORMANCE OF FISH PASSAGE STRUCTURES AT UPSTREAM BARRIERS TO MIGRATION. River Research and Applications, 28: 457-478. DOI: 10.1002/rra.1565.

Čada GF. 2001. The development of advanced hydroelectric turbines to improve fish passage survival. Fisheries, 26: 14-23. DOI: $10.1577 / 1548$ 8446(2001)026<0014:TDOAHT>2.0.CO;2.

Calles O, Greenberg L. 2009. Connectivity is a two-way street-the need for a holistic approach to fish passage problems in regulated rivers. River Research and Applications, 25: 1268-1286. DOI: 10.1002/rra.1228.

Campbell Grant EH, Lowe WH, Fagan WF. 2007. Living in the branches: population dynamics and ecological processes in dendritic networks. Ecol Lett, 10: 165-175. DOI: $10.1111 /$ j.1461-0248.2006.01007.X.

Cote D, Kehler DG, Bourne C, Wiersma YF. 2009. A new measure of longitudinal connectivity for stream networks. Landscape Ecol, 24: 101-113. DOI: 10.1007/s10980-008-9283-y.

Dale MRT, Fortin MJ. 2010. From graphs to spatial graphs. Annual Review of Ecology, Evolution, and Systematics, 41:21-38. DOI: 10.1146/annurev-ecolsys-102209144718.

De'ath G, Fabricius KE. 2000. Classification and regression trees: a powerful yet simple technique for ecological data analysis. Ecology, 81 : 3178-3192. DOI: 10.1890/00129658(2000)081[3178:CARTAP]2.0.CO;2. 
Deng ZQ, Carlson TJ, Dauble DD, Ploskey GR. 2011. Fish passage assessment of an advanced hydropower turbine and conventional turbine using blade-strike modeling. Energies, 4: 57-67. DOI: 10.3390/en4010057.

Dudgeon D, Arthington AH, Gessner MO, Kawabata Z-I, Knowler DJ, Lévêque C, Naiman RJ, Prieur-Richard A-H, eacute, egrave, ne, Soto D, Stiassny MLJ, Sullivan CA. 2006. Freshwater biodiversity: importance, threats, status and conservation challenges. Biological Reviews, 81: 163-182. DOI: 10.1017/S1464793105006950.

Erös T, Schmera D, Schick RS. 2011. Network thinking in riverscape conservation - A graph-based approach. Biological Conservation, 144: 184-192. DOI: 10.1016/j.biocon.2010.08.013.

Ferguson JW, Absolon RF, Carlson TJ, Sand ford BP. 2006. Evidence of delayed mortality on juvenile Pacific salmon passing through turbines at Columbia River dams. Transactions of the American Fisheries Society, 135: 139-150. DOI: 10.1577/T05080.1 .

Gauld NR, Campbell RNB, Lucas MC. 2013. Reduced flow impacts salmonid smolt emigration in a river with low-head weirs. Science of The Total Environment, 458460: 435-443. DOI: http://dx.doi.org/10.1016/j.scitotenv.2013.04.063.

Geris J, Tetzlaff D, Seibert J, Vis M, Soulsby C. 2015. Conceptual modelling to assess hydrological impacts and evaluate environmental flow scenarios in montane river systems regulated for hydropower. River Research and Applications, 31: 1066-1081. DOI: $10.1002 / \mathrm{rra} .2813$.

Gibson RJ. 1993. The Atlantic Salmon in Fresh-Water - Spawning, Rearing and Production. Reviews in Fish Biology and Fisheries, 3: 39-73. DOI: 10.1007/Bf00043297.

Gilarranz LJ, Bascompte J. 2012. Spatial network structure and metapopulation persistence. Journal of Theoretical Biology, 297: 11-16. DOI: 10.1016/j.jtbi.2011.11.027.

Goode JR, Buffington JM, Tonina D, Isaak DJ, Thurow RF, Wenger S, Nagel D, Luce C, Tetzlaff D, Soulsby C. 2013. Potential effects of climate change on streambed scour and risks to salmonid survival in snow-dominated mountain basins. Hydrological Processes, 27: 750-765.

Grill G, Lehner B, Lumsdon AE, MacDonald GK, Zarfl C, Reidy Liermann C. 2015. An index-based framework for assessing patterns and trends in river fragmentation and flow regulation by global dams at multiple scales. Environmental Research Letters, 10: 015001. DOI: 10.1088/1748-9326/10/1/015001.

Grill G, Ouellet Dallaire C, Fluet Chouinard E, Sindorf N, Lehner B. 2014. Development of new ind icators to evaluate river fragmentation and flow regulation at large scales: A case study for the Mekong River Basin. Ecological Indicators, 45: 148-159. DOI: 10.1016/j.ecolind.2014.03.026.

Gustafsson S. 2010. Migration losses of Atlantic salmon (Salmo salar L.) smolts at a hydropower station area in River Åbyälven, Northern Sweden. Passage fates at a reservoir, a power house and a bypass structure. In: Faculty of Forestry, Department of Wild life, Fish, and Environmental Studies, Swedish Univeristy of Agricultural Sciences, pp: 20 .

Imholt C, Soulsby C, Malcolm IA, Hrachowitz M, Gibbins CN, Langan S, Tetzlaff D. 2013. Influence of scale on thermal characteristics in a large montane river basin. River Research and Applications, 29: 403-419. DOI: 10.1002/rra.1608. 
Jackson HM, Gibbins CN, Soulsby C. 2007. Role of discharge and temperature variation in determining invertebrate community structure in a regulated river. River Research and Applications, 23: 651-669. DOI: 10.1002/rra.1006.

Jordan F, Benedek Z, Podani J. 2007. Quantifying positional importance in food webs: A comparison of centrality ind ic es. Ecological Modelling, 205: 270-275. DOI: 10.1016/j.ecolmode1.2007.02.032.

Keefer ML, Taylor GA, Garletts DF, Helms CK, Gauthier GA, Pierce TM, Caudill CC. 2013. High-head dams affect downstream fish passage timing and survival in the Middle Fork Willamette River. River Research and Applications, 29: 483-492. DOI: 10.1002/rra.1613.

Lazzaro G, Botter G. 2015. Run-of-river power plants in Alpine regions: Whither optimal capacity? Water Resources Research, 51:5658-5676. DOI: 10.1002/2014wr016642.

Leathwick JR, Elith J, Chadderton WL, Rowe D, Hastie T. 2008. Dispersal, disturbance and the contrasting biogeographies of New Zealand's diadromous and non-diadromous fish species. Journal of Biogeo graphy, 35: 1481-1497. DOI: 10.1111/j.13652699.2008.01887.x.

Mahlum S, Kehler D, Cote D, Wiersma YF, Stanfield L. 2014. Assessing the biological relevance of aquatic connectivity to stream fish communities. Canadian Journal of Fisheries and Aquatic Sciences: 1-12. DOI: 10.1139/cjfas-2013-0646.

Malcolm IA, Gibbins CN, Soulsby C, Tetzlaff D, Moir HJ. 2012. The influence of hydrology and hydraulics on salmonids between spawning and emergence: implications for the management of flows in regulated rivers. Fisheries Management and Ecology, 19: 464-474. DOI: 10.1111/j.1365-2400.2011.00836.x.

Marcus WA, Legleiter CJ, Aspinall RJ, Boardman JW, Crabtree RL. 2003. High spatial resolution hyperspectral mapping of in-stream habitats, depths, and woody debris in mountain streams. Geomorphology, 55: 363-380. DOI: 10.1016/S0169555X(03)00150-8.

Mathur D, Heisey PG, Euston ET, Skalski JR, Hays S. 1996. Turbine passage survival estimation for chinook salmon smolts (Oncorhynchus tshawytscha) at a large dam on the Columbia River. Canadian Journal of Fisheries and Aquatic Sciences, 53: 542549. DOI: 10.1139/f95-206.

McCormick SD, Hansen LP, Quinn TP, Saunders RL. 1998. Movement, migration, and smolting of Atlantic salmon (Salmo salar). Canadian Journal of Fisheries and Aquatic Sciences, 55: 77-92. DOI: 10.1139/d98-011.

McKay SK, Schramski JR, Conyngham JN, Fischenich JC. 2013. Assessing upstream fish passage connectivity with network analys is. Ecological Applications, 23: 1396-1409. DOI: $10.1890 / 12-1564.1$.

Millar CP, Millidine KJ, Middlemas SJ, Malcolm IA. 2015. Development of a model for predicting large scale spatio-temporal variability in juvenile fish abundance from electrofishing data. Scottish Marine and Freshwater Science Report, 6. DOI: 10.7489/1616-1.

Milner NJ, Solomon DJ, Smith GW. 2012. The role of river flow in the migration of adult Atlantic salmon, Salmo salar, through estuaries and rivers. Fisheries Management and Ecology, 19: 537-547. DOI: 10.1111/fme.12011. 
Moir HJ, Gibbins CN, Soulsby C, Webb J. 2004. Linking channel geomorphic characteristics to spatial patterns of spawning activity and discharge use by Atlantic Salmon (Salmo salar L.). Geomorphology, 60: 21-35. DOI: 10.1016/j.geomorph.2003.07.014.

Montgomery DR, Buffington JM. 1997. Channel-reach morphology in mountain drainage basins. Geological Society of America Bulletin, 109: 596-611. DOI: 10.1130/00167606(1997)109<0596: crmimd $>2.3 . c 0 ; 2$.

Mulet RC. 2004. The geomorphical and hydro-ecological impacts of flow regulation in the River Lyon. In: Department of Soils and Environmental Science, University of Lleida, pp: 77.

Nislow KH, Armstrong JD. 2012. Towards a life-history-based management framework for the effects of flow on juvenile salmonids in streams and rivers. Fisheries Management and Ecology, 19: 451-463. DOI: 10.1111/j.1365-2400.2011.00810.x.

Noonan MJ, Grant JWA, Jackson CD. 2012. A quantitative assessment of fish passage efficiency. Fish and Fisheries, 13: 450-464. DOI: 10.1111/j.1467-2979.2011.00445.x.

Peterson EE, Ver Hoef JM, Isaak DJ, Falke JA, Fortin M-J, Jordan CE, McNyset K, Monestiez P, Ruesch AS, Sengupta A, Som N, Steel EA, Theobald DM, Torgersen CE, Wenger SJ. 2013. Modelling dendritic ecological networks in space: an integrated network perspective. Ecology Letters, 16: 707-719. DOI: 10.1111/ele.12084.

Poff NL, Olden JD, Merritt DM, Pepin DM. 2007. Homogenization of regional river dynamics by dams and global biodiversity implications. Proceedings of the National Academy of Sciences, 104: 5732-5737. DOI: 10.1073/pnas.0609812104.

Pringle CM. 2001. Hydrologic connectivity and the management of biological reserves: a global perspective. Ecological Applications, 11: 981-998. DOI: 10.2307/3061006.

Quinlan E, Gibbins C, Malcolm I, Batalla R, Vericat D, Hastie L. 2015. A review of the physical habitat requirements and research priorities needed to und erpin conservation of the endangered freshwater pearl mussel Margaritifera margaritifera. Aquatic Conservation-Marine and Freshwater Ecosystems, 25: 107-124. DOI: $10.1002 /$ aqc. 2484 .

Rubio Ln, Saura S. 2012. Assessing the importance of individual habitat patches as irreplaceable connecting elements: An analysis of simulated and real landscape data. Ecological Complexity, 11: 28-37. DOI: 10.1016/j.ecocom.2012.01.003.

Scheuerell MD, Zabel RW, Sand ford BP. 2009. Relating juvenile migration timing and survival to adulthood in two species of threatened Pacific salmon (Oncorhynchus spp.). Journal of Applied Ecology, 46: 983-990. DOI: 10.1111/j.13652664.2009.01693.x.

Schick RS, Lindley ST. 2007. Directed connectivity among fish populations in a riverine network. Journal of Applied Ecology, 44: 1116-1126. DOI: 10.1111/j.13652664.2007.01383.X.

Scruton DA, Pennell CJ, Bourgeois CE, Goosney RF, King L, Booth RK, Eddy W, Porter TR, Ollerhead LMN, Clarke KD. 2008. Hydroelectricity and fish: a synops is of comprehensive studies of upstream and downstream passage of anadromous wild Atlantic salmon, Salmo salar, on the Exploits River, Canada. Hydrobiologia, 609: 225-239. DOI: 10.1007/s10750-008-9410-4. 
Segurado P, Branco P, Ferreira M. 2013. Prioritizing restoration of structural connectivity in rivers: a graph based approach. Landscape Ecol, 28: 1231-1238. DOI:

10.1007/s10980-013-9883-z.

Shaw EA, Lange E, Shucksmith JD, Lerner DN. 2016. Importance of partial barriers and temporal variation in flow when modelling connectivity in fragmented river systems. Ecological Engineering, 91: 515-528. DOI:

http://dx.doi.org/10.1016/i.ecoleng.2016.01.030.

Soulsby C, BirkelC, Geris J, Tetzlaff D. 2015. The isotope hydrology of a large river system regulated for hydropower. River Research and Applications, 31:335-349. DOI: 10.1002/rra.2740.

Stephenson JR, Gingerich AJ, Brown RS, Pflugrath BD, Deng ZQ, Carlson TJ, Langeslay MJ, Ahmann ML, Johnson RL, Seaburg AG. 2010. Assessing barotrauma in neutrally and negatively buoyant juvenile salmonids exposed to simulated hydro-turbine passage using a mobile aquatic barotrauma labora tory. Fisheries Research, 106: 271 278. DOI: $10.1016 /$ j. fishres.2010.08.006.

Stich DS, Zydlewski GB, Kocik JF, Zydlewski JD. 2015. Linking behavior, physiology, and survival of Atlantic salmon smolts during estuary migration. Marine and Coastal Fisheries, 7: 68-86. DOI: 10.1080/19425120.2015.1007185.

Tamminga A, Hugenholtz C, Eaton B, Lapointe M. 2015. Hyperspatial remote sensing of channel reach morphology and hydraulic fish habitat using an Unmanned Aerial Vehicle (UAV): a first assessment in the context of river research and management. River Research and Applications, 31: 379-391. DOI: 10.1002/rra.2743.

Tetzlaff D, Gibbins C, Bacon PJ, Youngson AF, Soulsby C. 2008. Influence of hydrological regimes on the pre-spawning entry of Atlantic salmon (Salmo salar L.) into an upland river. River research and applications, 24: 528-542. DOI: 10.1002/rra.1144.

Tetzlaff D, Soulsby C, Bacon PJ, Youngson AF, Gibbins C, Malcolm IA. 2007. Connectivity between landscapes and riverscapes - a unifying theme in integrating hydrology and ecology in catchment science? Hydrological Processes, 21: 1385-1389. DOI: 10.1002/hyp.6701.

Thorstad EB, Whoriskey F, Uglem I, Moore A, Rikardsen AH, Finstad B. 2012. A critical life stage of the Atlantic salmon Salmo salar: behaviour and survival during the smolt and initial post-smolt migration. Journal of F ish Biology, 81: 500-542. DOI: 10.1111/j.1095-8649.2012.03370.x.

Tockner K, Pusch M, Gessner J, Wolter C. 2011. Domesticated ecosystems and novel communities: challenges for the management of large rivers. Ecohydrology \& Hydrobiology, 11: 167-174. DOI: 10.2478/v10104-011-0045-0.

Urban DL, Minor ES, Treml EA, Schick RS. 2009. Graph models of habitat mosaics. Ecology Letters, 12:260-273. DOI: 10.1111/j.1461-0248.2008.01271.x.

Woodget AS, Visser F, Maddock IP, Carbonneau PE. 2016. The Accuracy and Reliability of Traditional Surface Flow Type Mapping: Is it Time for a New Method of Characterizing Physical River Habitat? River Research and Applications, 32: 19021914. DOI: 10.1002/rra.3047.

Zarfl C, Lumsdon AE, Berlekamp J, Tydecks L, Tockner K. 2014. A global boom in hydropower dam construction. Aquatic Sciences, 77: 161-170. DOI: 10.1007/s00027014-0377-0. 
Table 1: Types of data used in the analysis, description of data, and source.

\begin{tabular}{|c|c|c|}
\hline Data & Description & Source \\
\hline DTM & $\begin{array}{c}\text { Raster data, 5m } \\
\text { resolution }\end{array}$ & $\begin{array}{c}\text { Edina Digimap, Ordnance Survey. } \\
\text { URL: http://digimap.edina.ac.uk }\end{array}$ \\
\hline $\begin{array}{c}\text { Ordnance Survey Mastermap } \\
\text { (OS Mastermap) }\end{array}$ & Topography & $\begin{array}{c}\text { Edina Digimap, Ordnance Survey. } \\
\text { URL: } \text { http://digimap.edina.ac.uk }\end{array}$ \\
\hline $\begin{array}{c}\text { Ordnance Survey Mastermap } \\
\text { for South Lanarkshire and } \\
\text { Perth-Kinross }\end{array}$ & River polyline data & $\begin{array}{c}\text { Edina Digimap, Ordnance Survey. } \\
\text { URL: http://digimap.edina.ac.uk }\end{array}$ \\
(OSMM_SLA_PerK) & & James Hutton Institute, Scotland \\
\hline Barriers to fish migration & Point data & SEPA, Marine Scotland Science \\
\hline Reach Classification Glen & River polyline \\
Lyon & data/50m reaches & (Mulet, 2004) \\
\hline Historic Ordnance Survey & $\begin{array}{c}\text { 1-inch OS map for } \\
\text { Kastermap }\end{array}$ & Killin \& Loch \\
Rannoch area; period & National Library of Scotland. \\
& URL: $\underline{\text { http://maps.nls.uk/geo/explore }}$ \\
\hline
\end{tabular}


Table 2: Quality multiplier values for the different reach types present in the River Lyon. Values range between 0 and 1, with higher quality habitat having values closer to 1 and vice versa.

\begin{tabular}{|c|c|c|c|}
\hline Reach type & Quality multiplier & Reach type & Quality multiplier \\
\hline Bedrock (B) & 0 & $\begin{array}{c}\text { Bedrock/Cascade } \\
\text { (B/C) }\end{array}$ & 0 \\
\hline Bedrock/Pool-riffle & 0.1 & Cascade (C) & 0 \\
\hline Loch & 0.01 & Plane-Bed (PB) & 0.25 \\
\hline $\begin{array}{c}\text { Plane-Bed/Pool-Riffle } \\
\text { (PB/PR) }\end{array}$ & 0.5 & Pool-Riffle (PR) & 0.6 \\
\hline $\begin{array}{c}\text { Pool-R iffle/Wandering } \\
\text { (PR/W) }\end{array}$ & 0.5 & Step-Pool (SP) & 0.15 \\
\hline
\end{tabular}


Table 3: Simulation results for the $\mathrm{DCI}_{\mathrm{d}}$ connectivity index. Impact of barriers considered regardless of origin, purely as barrier to fish migration. Passability values range between 0 and 1, where 0 represents and impassable barrier and 1 a fully passable barrier. Values for $\mathrm{DCI}_{\mathrm{d}}$ for the three weighting approaches are given as cumulative percentage of connectivity after barriers are added from top to bottom; a value of $100 \%$ would represent a scenario where the river network is fully connected.

\begin{tabular}{|c|c|c|c|c|}
\hline & & \multicolumn{3}{|c|}{ DCI $_{\mathbf{d}}(\mathbf{\%})$} \\
\hline Barrier & Pass ability & Wetted Are a & Spawning Habitat & Fry Production \\
\hline Lubreoch & 0 & 23.5 & 89.7 & 95.0 \\
\hline Small dam on tributary (hi) & 0 & 23.4 & 89.4 & 94.3 \\
\hline Stronuich & 1 & 23.4 & 89.4 & 94.3 \\
\hline Waterfall on mainstem(hi) & 0.8 & 21.6 & 86.0 & 89.1 \\
\hline Small dam on tributary (lo) & 0 & 21.6 & 85.9 & 88.9 \\
\hline Waterfall on mainstem (lo) & 0.8 & 18.2 & 73.9 & 74.7 \\
\hline
\end{tabular}


Table 4: Simulation results for the $\mathrm{DCI}_{\mathrm{d}}$ connectivity index. Impact of artificial barriers considered as percentage of natural connectivity. Values for $\mathrm{DCI}_{\mathrm{d}}$ for the three weighting approaches are given as cumulative percentage of natural connectivity after barriers are added from top to bottom; a value of $100 \%$ would represent a scenario where the artificial barrier do not lead to a further decrease of natural connectivity.

\begin{tabular}{|c|c|c|c|}
\hline & \multicolumn{3}{|c|}{ DCId (\% of natural connectivity) } \\
\hline Barrier & Wetted Area & Spawning Habitat & Fry Production \\
\hline Lubreoch & 27.2 & 91.8 & 95.9 \\
\hline Small dam on tributary (hi) & 27.1 & 91.6 & 95.4 \\
\hline Stronuich & 27.1 & 91.6 & 95.4 \\
\hline Small dam on tributary (lo) & 27.0 & 91.6 & 95.2 \\
\hline
\end{tabular}
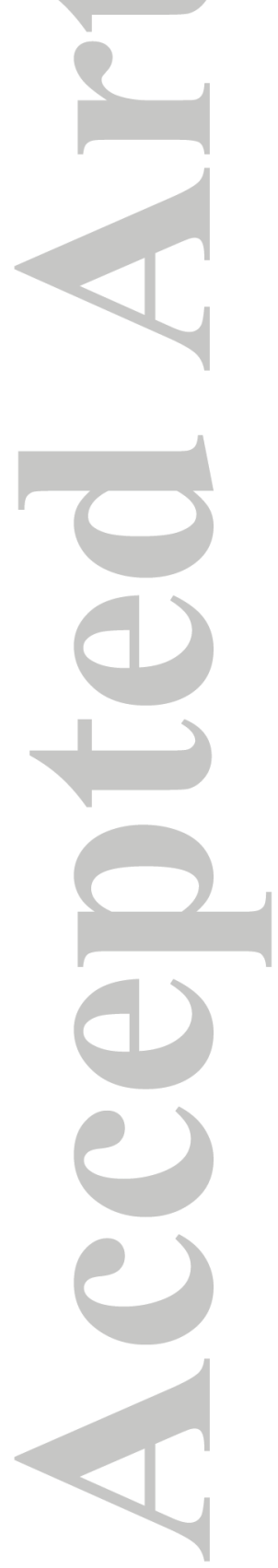


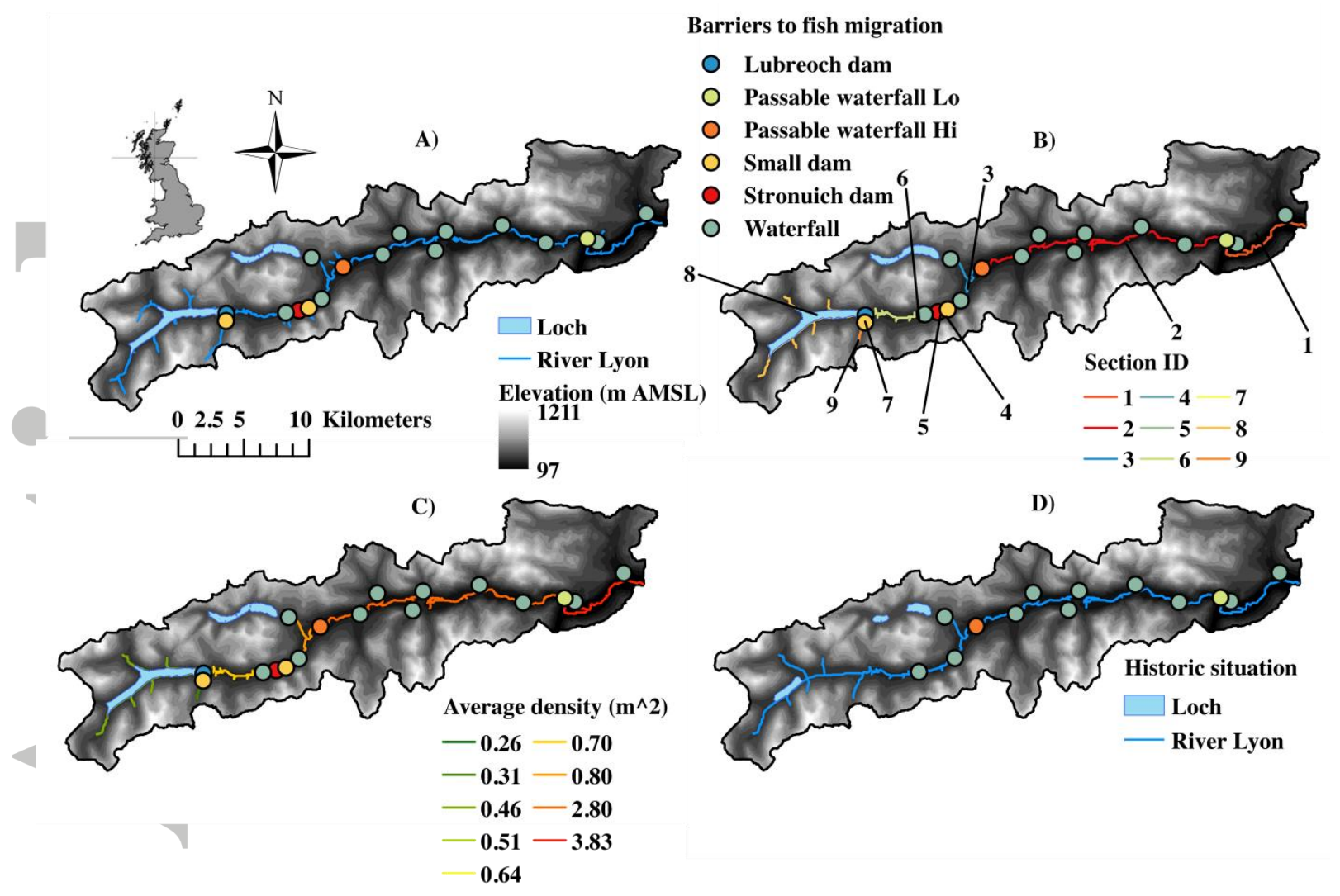

Figure 1: A) topography; B) 9 sections of the simplified river network; C) mean density per metre square for each section, based on Millar et al., 2015; D) historic map showing river network pre-regulation, note dams not present and lochs smaller in size, loch at Stronuich not present (based on OS map, period prior to 1930, from National library of Scotland). 

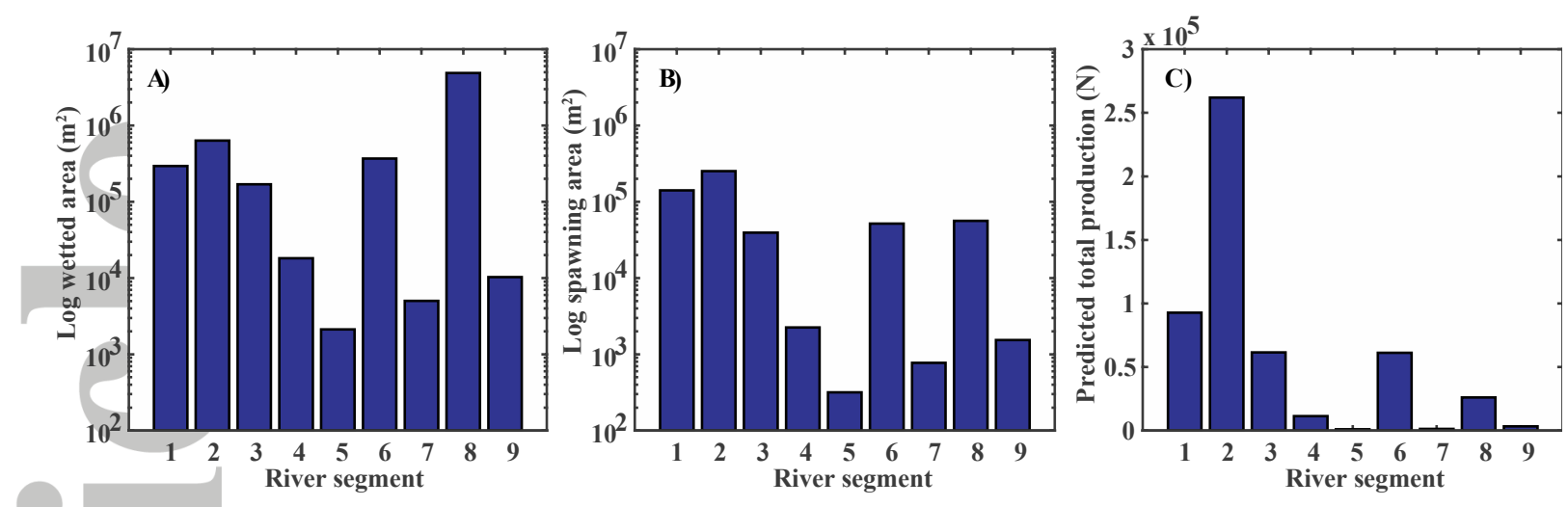

Figure 2: A) indicates the Log of wetted area for each reach (as indicated in Figure 1); B) indicates the Log of the area weighted by suitability for spawning; C) indicates the predicted total juvenile production, based on the national fry density model.

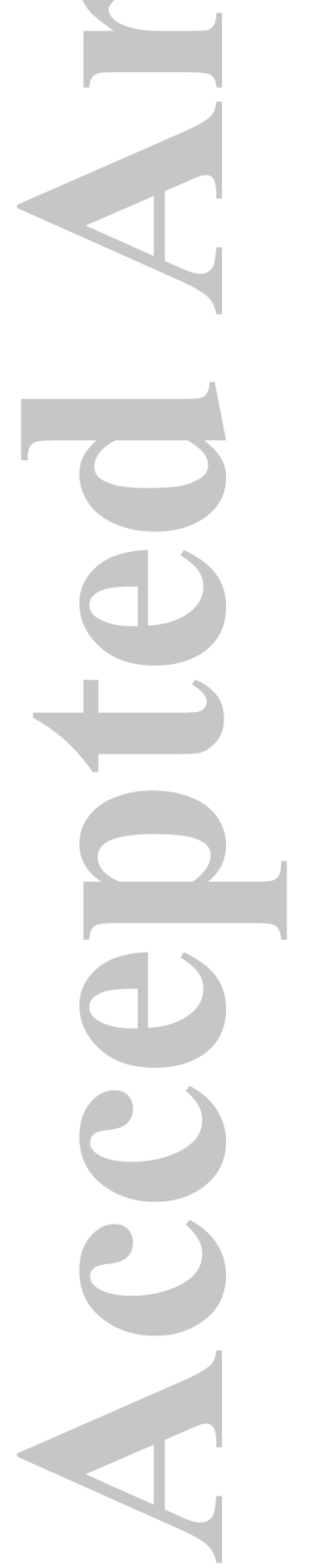



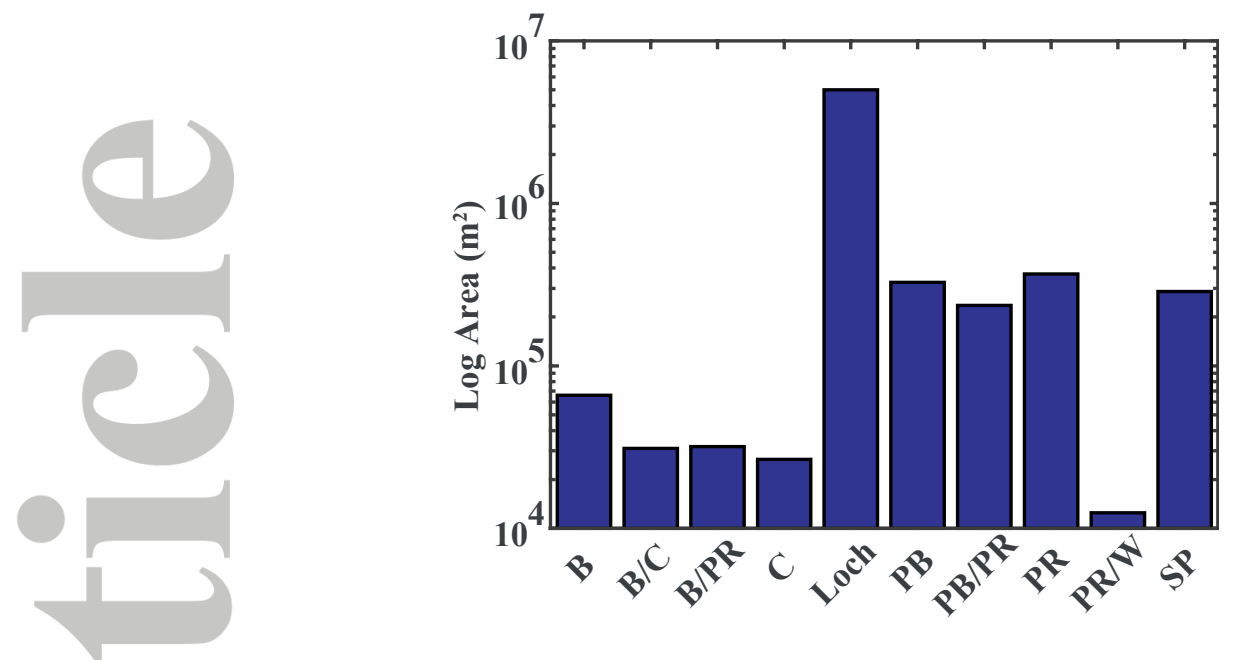

Figure 3: Log of the area in square metres for the classified reach types, as they are present in the River Lyon (see Table 2 for abbreviations).
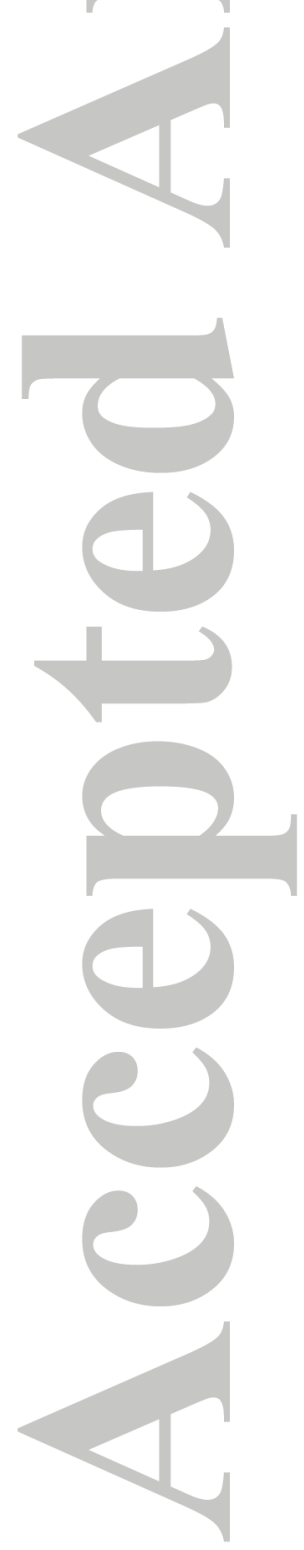


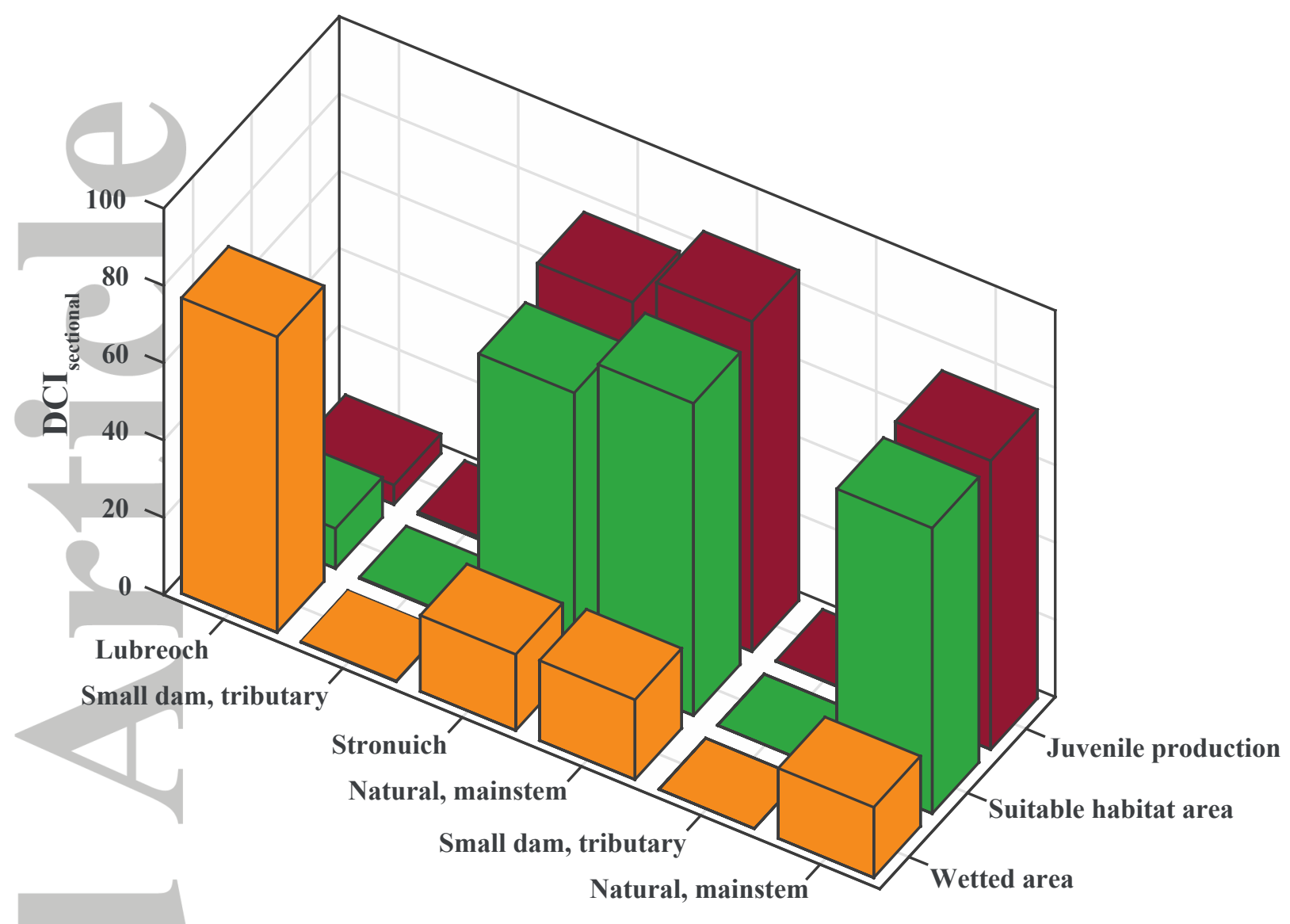

Figure 4: Connectivity for sections in the system between the different barriers (i.e., ability to travel from one section to the rest of the network, passing a barrier). Sectional connectivity indicates connectivity for each section to the rest of the river network, i.e., it does not reflect the connectivity of the whole system like $\mathrm{DCI}_{\mathrm{d}}$ (see Table 3 ). 